\title{
Surface Pre-Treatment of Batch-Galvanized Components for Adhesively Bonded Assemblies
}

\author{
By Johannes Stahl ${ }^{*}$ \\ Paul Ludwig Geiss"
}

The strength of adhesively bonded joints depends on the cohesive strength as well as on the adhesion between the adhesive and adherent. In case of batchgalvanized steel, using zinc coating, the composition of the zinc layer and zinc layer phases can have a crucial impact on the compound's stability. In order to produce reliable and durable bonds the zinc layer surface has to be pretreated. Suitable preparation methods for the terms of the constructive industry must be chosen in respect to the specific surface characteristics of the zinc coating. Compared to the sweep-blasting process, pickling offers an economical surface pre-treatment method for the batch-galvanized components.

Keywords: Adhesion, Batch-galvanized steel, Durability, Pickling, pretreatment, Wedge test

\section{Introduction}

In Europe, each year, approximately 6 million tons of steel are protected against corrosion by batch-galvanization (Garcia de Lucas, 2010). Because of its good protection performance, lasting for at least several decades, a large variety of batch hot-dip galvanized (HDG) components is used in the building and construction industry. A recently completed SME-related research project on "Hot-dip galvanizing for steel and composite bridges" (Ungermann et al., 2014) points out new fields of application in this sector. In the majority of usecases today, batch-galvanized components are connected by bolting or welding. Due to that, the zinc coating is often destroyed or disrupted locally. Bonding as a connection method would normally not result in such impairments of the coating. Adhesive bonding, therefore, offers a promising alternative to improve the quality of joints of batch-galvanized components, regarding their specific surface characteristics. The strength of adhesively bonded joints depends on the cohesive strength as well as on the adhesion between the adhesive and adherent. Primarily, the composition of the zinc layer depends on the effective galvanization parameters, such as the temperature of the zinc bath, and the fraction of silicon in the steel alloy (Thiele and Schulz, 2006). In order to characterize the layered structure of batch-galvanized steel,

\footnotetext{
* Research Assistant, University of Kaiserslautern, Germany.

† Professor, University of Kaiserslautern, Germany .
} 
micro-grids were prepared. Figure 1 shows a micrograph of a representative zinc layer. The phase nucleation in the zinc layer is sequentially starting with the $\Gamma$-phase (Wolczynski et al., 2014). The existence of a continuous $\Gamma$-phase has a strong impact on the formation of the zinc layer (Che and $\mathrm{Lu}, 2005$ ).

Figure 1. Micrograph of a Representative Zinc Layer

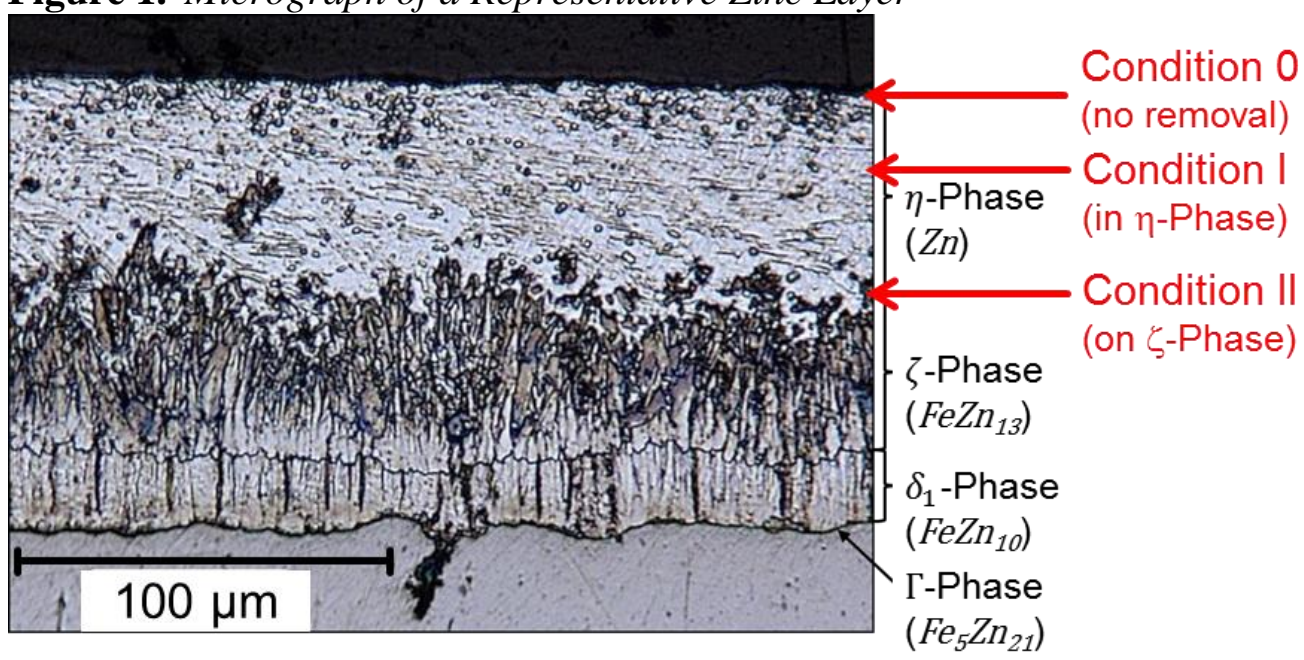

The adhesion between adherent and adhesive depends on the surface condition of the zinc layer. Most importantly, the zinc layer has to be free from grease, soluble salts and adherently loose particles. The chemical composition of the surface can vary depending on the ageing conditions during the transport or storage of the batch-galvanized component. Investigations in the field of duplex systems indicate a different adhesion between epoxy-based paints and outdoor-weathered or not-weathered batch-galvanized steel (Van Eijnsbergen, 1994). Tensile-Shear Tests on centrifuged batch-galvanized steel ( $\eta$-phase removed) hypothesize that the adhesion between adhesive and zinc layer is dependent on the specific zinc layer phase on which the adhesive is applied (Stahl and Geiss, 2015). In Figure 1 Condition 0 denotes a state in which the $\eta$ phase is still fully in-tact. Other zinc layer conditions investigated in this paper are also indicated in Figure 1: Condition I denotes a state in which the $\eta$-phase is partially removed. Condition II denotes a state in which the $\eta$-phase is completely removed and the adhesive is applied on top of the $\zeta$-phase. Before the bonding is carried out, surface pretreatment methods are deployed, which can partially or fully remove the zinc layer phases, so that it can be investigated how the durability of the bond depends on the specific zinc layer phases on which an adhesive is applied.

\section{Selected Material}

\section{Adherents}

To produce a set of consistent zinc layer phases, only identically shaped mild steel sheets (dimensions: $260 \mathrm{~mm} \times 25 \mathrm{~mm} \times 10 \mathrm{~mm}$ ) with the chemical 
composition given in Table 1Table 1 were batch hot-dip galvanized by Voigt \& Schweitzer GmbH \& Co. KG. The constellation of the zinc layer phases is primarily depending on the content of silicon $(0.17 \mathrm{~m}-\%$, Sebisty-Area) in the steel sheets (Katzung and Rittig, 1997).

Table 1. Chemical Composition of the Used Steel Sheets According to Certification Report 3.1 by EN 10204

\begin{tabular}{|c|c|c|c|c|c|c|c|c|c|}
\hline $\begin{array}{c}\text { Si- } \\
\text { content }\end{array}$ & Steel grade & \multicolumn{6}{|c|}{ Content of other alloy elements [m-\%] } \\
\hline$[\mathrm{m}-\%]$ & $(\mathrm{EN} \mathrm{10025)}$ & $\mathrm{C}$ & $\mathrm{Mn}$ & $\mathrm{S}$ & $\mathrm{P}$ & $\mathrm{Cr}$ & $\mathrm{Ni}$ & $\mathrm{Cu}$ & $\mathrm{N}$ \\
\hline 0.17 & S235JR+N & 0.14 & 0.48 & 0.018 & 0.010 & 0.063 & 0.085 & 0.186 & 0.009 \\
\hline
\end{tabular}

The batch-galvanizing process was carried out using a conventional zinc bath according to ASTM B6 at a temperature of approximately $840{ }^{\circ} \mathrm{F}$ (449 $\left.{ }^{\circ} \mathrm{C}\right)$. The combination of used steel alloy and effective process parameters lead to an average zinc layer thickness of $108.2 \mu \mathrm{m}$ with a standard deviation of 5.2 $\mu \mathrm{m}$. The layer thickness was determined by a magnet-inductive measuring system (eXactoFN 180-1102, Elektro Physik Dr. Steingroever GmbH \& Co. $\mathrm{KG})$. The analysis of micrographs shows that the thickness of the different zinc layer phases was approximately $25 \mu \mathrm{m}$ for the $\eta$-phase, $65 \mu \mathrm{m}$ for the $\zeta$-phase and $20 \mu \mathrm{m}$ for the $\delta_{1}$-phase, respectively.

\section{Adhesives}

Three adhesives were selected in respect to their application properties to prepare modified wedge test specimen (Table 2). Curing conditions of the specimen were 24 hours by $23{ }^{\circ} \mathrm{C}$, then 2 hours by $80^{\circ} \mathrm{C}$ and 6 days by $23^{\circ} \mathrm{C}$.

Table 2. Selected Adhesives

\begin{tabular}{|l|c|c|c|}
\hline Adhesive & Körapur $^{\circledR}$ 666 / 30 & $\begin{array}{c}\text { Scotch Weld }^{\text {TM }} \\
\mathbf{7 2 6 0} \text { B/A FC NS }\end{array}$ & Sika Power $^{\circledR}$-477 R \\
\hline Abbreviation & KP 666 & SW 7260 & SP 477 \\
\hline Color & beige & black & red \\
\hline Chemical base & 2C Polyurethane & 2C Epoxy & 2C Epoxy \\
\hline Pot life [Minutes] & 30 & 90 & 30 \\
\hline Viscous properties & pasty & pasty & pasty \\
\hline $\begin{array}{l}\text { Maximum tensile } \\
\text { sheer strength } \\
\text { following EN 14869-2 } \\
\text { [MPa] }\end{array}$ & 13.1 & 26.7 & 24.5 \\
\hline
\end{tabular}




\section{Experimental Investigation}

\section{Surface Pretreatment}

Sweep-Blasting

Surface pretreatment by sweep-blasting is state of the art for duplex systems in the field of coating technology. According to the handbook of hotdip galvanization (Maass and Peissker, 2011) sweep-blasting is the safest surface pretreatment method for HDG-steel. Surface cleaning and roughening occurs by slightly blasting the zinc surface using metallic or nonmetallic abrasives and compressed air, free of oil and water. The zinc layer must not be completely removed or locally destroyed due to sweep-blasting-processes. The most significant parameters controlling the sweep-blasting-process are material and grain size of the used grit, angle of incidence, blasting pressure and distance of nozzle to the surface.

To remove the $\eta$-phase of the zinc layer (thickness of approximately 25 $\mu \mathrm{m})$ sweep-blasting was performed using the following parameters:

- Grit: Corundum, white

- Grain size $=125-180 \mu \mathrm{m}$

- Angle of incidence $=30^{\circ}$

- Blasting pressure $=5$ bar

- Duration-time $=8$ to 12 minutes

The exact duration of the pre-treatment depends on the desired effective reduction of the layer thickness. Figure 2Figure 2 shows a HDG-surface, structured by sweep-blasting, compared to the non-pretreated HDG-surface. Table 3contains the statistics computed over ten sample values of the layer thickness before and after sweep-blasting.

Figure 2. Surface before and after Sweep-blasting
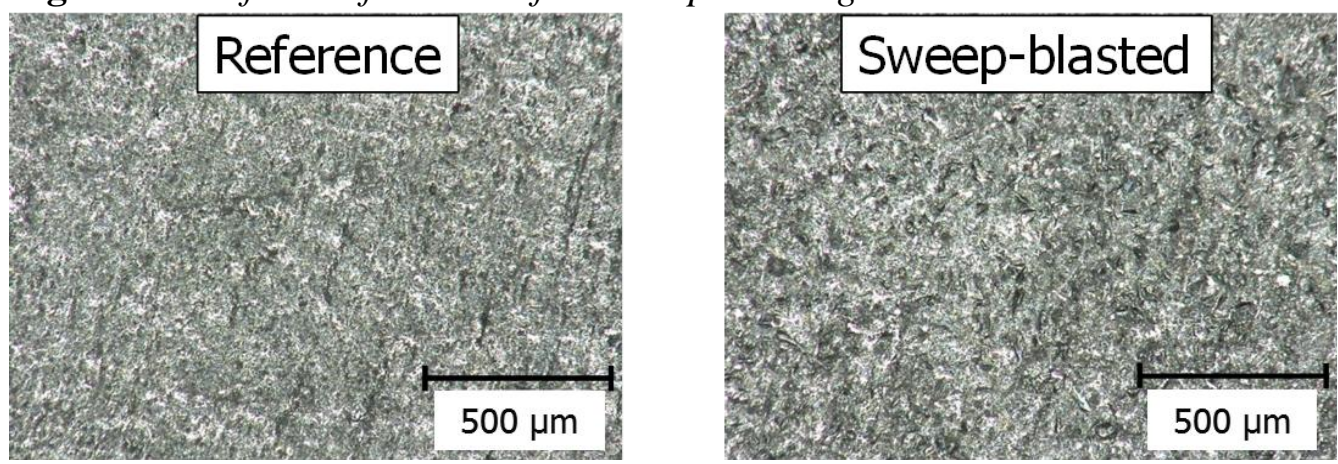
Table 3. Layer Thickness before and after Sweep-blasting

\begin{tabular}{|c|c|c|c|c|c|}
\hline \multirow{2}{*}{ Condition } & Mean & $\begin{array}{c}\text { Standard } \\
\text { deviation }\end{array}$ & Maximum & Minimum & $\begin{array}{c}\text { Average } \\
\text { reduction }\end{array}$ \\
\cline { 2 - 5 } & \multicolumn{5}{|c|}{$[\boldsymbol{\mu m}]$} \\
\hline $\begin{array}{c}\text { Before sweep- } \\
\text { blasting }\end{array}$ & 107.9 & 5.3 & 116.5 & 99.8 & \multirow{2}{*}{22.5} \\
\hline $\begin{array}{c}\text { After sweep- } \\
\text { blasting }\end{array}$ & 85.4 & 6.1 & 94.7 & 75.7 & \\
\hline
\end{tabular}

\section{$\underline{\text { Pickling }}$}

\section{Motivation and Selection}

Compared to the sweep-blasting-process, pickling offers an economically more attractive method to pretreat batch-galvanized components. A reduction of the zinc layer can be achieved without imposing mechanical stress to the zinc layer phases. Based on a search of literature and product recommendations regarding the field of coating technology a screening of cleaning and pickling solutions was done. The solutions were classified as a function of their ablation rate for HDG-steel determined by dipping. According to given exclusion and quality criteria, regarding application and health requirements, ten pickling solutions were selected, which can be used to partially remove the zinc layer in the range of the $\eta$-phase (approximately $25 \mu \mathrm{m}$ ). Among others, criteria for exclusion included usage of carcinogenic or rather toxic substances (e.g. hydrofluoric acid).

Based on the composition of the zinc layer compound in the section "Selected Material", the ten pickling solutions were applied by dipping or spraying on the HDG specimens. The results regarding the impact on the $\eta$ phase were compared using the wedge test according to EN 14444. Details on carrying out the wedge test according to EN 14444 will be described in subsection "Wedge Test". These preliminary test results were used to select the two most promising pickling solutions among the ten pre-selected ones which would most likely be the best suited ones for the pre-treatment of HDG steel for adhesively bonded joints due to their residual contact length.

\section{Pickling by Dipping}

Pickling by dipping was performed using the pickling solution "SurTec 479" (SurTec International GmbH). The hydrochloric acid-based product contains, among others, inhibitors to protect the ferric-basis material of the steel sheet. To remove the $\eta$-phase by dipping it in SurTec ${ }^{\circledR} 479$ and to establish Condition II in Figure 1, an exposure time of 15 to 25 minutes was necessary. After that time the reduction of the zinc layer thickness was approximately $25 \mu \mathrm{m}$, which corresponds to the average thickness of the $\eta$ phase. The pickling process was stopped by rinsing the steel sheets in two rinsing tubes filled with deionized water (conductance $<10 \mu \mathrm{S}$ ). The validation of the targeted condition was done by the determination of the residual layer thickness by the magnet-inductive measuring system (eXactoFN 180-1102, Elektro Physik Dr. Steingroever GmbH \& Co. KG). Table 4Table 4 contains 
the statistics computed over ten sample values of the layer thickness before and after pickling by dipping. The partial removal of the zinc layer phases was also spot-checked by using micrographs of pre-treated surfaces.

Table 4. Layer Thickness before and after Pickling by Dipping

\begin{tabular}{|c|c|c|c|c|c|}
\hline \multirow{2}{*}{ Condition } & Mean & $\begin{array}{c}\text { Standard } \\
\text { deviation }\end{array}$ & Maximum & Minimum & $\begin{array}{c}\text { Average } \\
\text { reduction }\end{array}$ \\
\cline { 2 - 5 } & \multicolumn{5}{|c|}{$[\boldsymbol{\mu m}]$} \\
\hline $\begin{array}{c}\text { Before pickling } \\
\text { by dipping }\end{array}$ & 108.1 & 5.4 & 116.7 & 99.4 & 24.4 \\
\hline $\begin{array}{c}\text { After pickling by } \\
\text { dipping }\end{array}$ & 83.7 & 11.4 & 98.5 & 63.5 & \\
\hline
\end{tabular}

\section{Pickling by Spraying}

Among the pickling solutions that are supposed to be applied by spraying, the cleaning agent "Bref Power" ${ }^{\circledR}$ (Henkel AG \& Co. KGaA) showed, within the examined solutions, the biggest residual contact length using the wedge test. The ablation rate on HDG steel was approximately $0.15 \mu \mathrm{m} /$ minute. During the pickling process it has to be ensured that the surface of the zinc layer cannot dry up. A new solution has to be applied over time before the surface dries up. To partially remove the $\eta$-phase of the zinc layer and to establish Condition I ("in $\eta$-phase") in Figure 1, the solution was applied over 90 minutes. Table 5Table 5 contains the statistics computed over ten sample values of the layer thickness before and after pickling by spraying with "Bref Power, ${ }^{\circledR}$.

Table 5. Layer Thickness before and after Pickling by Spraying

\begin{tabular}{|c|c|c|c|c|c|}
\hline \multirow{2}{*}{ Condition } & Mean & $\begin{array}{c}\text { Standard } \\
\text { deviation }\end{array}$ & Maximum & Minimum & $\begin{array}{c}\text { Average } \\
\text { reduction }\end{array}$ \\
\cline { 2 - 5 } & \multicolumn{5}{|c|}{$[\boldsymbol{\mu m}]$} \\
\hline $\begin{array}{c}\text { Before pickling } \\
\text { by spraying }\end{array}$ & 109.6 & 5.4 & 118.3 & 101.1 & 12.9 \\
\hline $\begin{array}{c}\text { After pickling by } \\
\text { spraying }\end{array}$ & 96.7 & 7.1 & 107.6 & 85.9 & \\
\hline
\end{tabular}

\section{Mild Grinding}

To establish Condition 0 ("on $\eta$-phase") in Figure 1, the surface of the zinc layer has to be free from graces, soluble salts and adherently loose particles. A mild grinding with ductile abrasive was performed to remove the adherently loose particles. Before and after grinding, the thickness of the zinc layer was consistent within the standard deviation. Both, not-weathered HDG steel and HDG steel outdoor-weathered in Kaiserslautern, Germany, between December 2013 and May 2014, were pre-treated by mild grinding.

\section{Wedge Test}

The superposition of mechanical stress and climatic influence is characteristic for the wedge test. This test demonstrates the performance of the 
surface pre-treatment in combination with the used adhesives for bonding. The wedge test method was selected to verify the durability of batch-galvanized adhesively bonded joints under exposure to standardized accelerated ageing conditions. The geometry of the wedge test specimen according to EN 14444 was modified to account for the HDG process and the dimensions of the selected steel sheets (Figure 3). After the aforementioned surface pretreatments were accomplished, the adherents were degreased and the pickling deposit was removed using acetone. The three adhesives were applied and cured as in subsection "Adhesives".

By inserting a wedge a mechanical peel force is applied on the used adhesive. In contrast to EN 14444 this was not leading to a crack immediately. The height of the wedge and the bonded length of the specimens were chosen dependent on the selected adhesive, so that the applied mechanical stress was half of the crack initiation stress for $23^{\circ} \mathrm{C}$.

Crack initiation should start while the superposition of accelerated ageing conditions takes place. The specimens were exposed to a climate corrosion test according to VDA 621-415 (VDA, 1982) and to an alternating climate test according to VW PV 1200 (VW, 2004).

Figure 3. Wedge Test According to EN 14444 (Top) and Modified Version for HDG-specimen (Bottom)

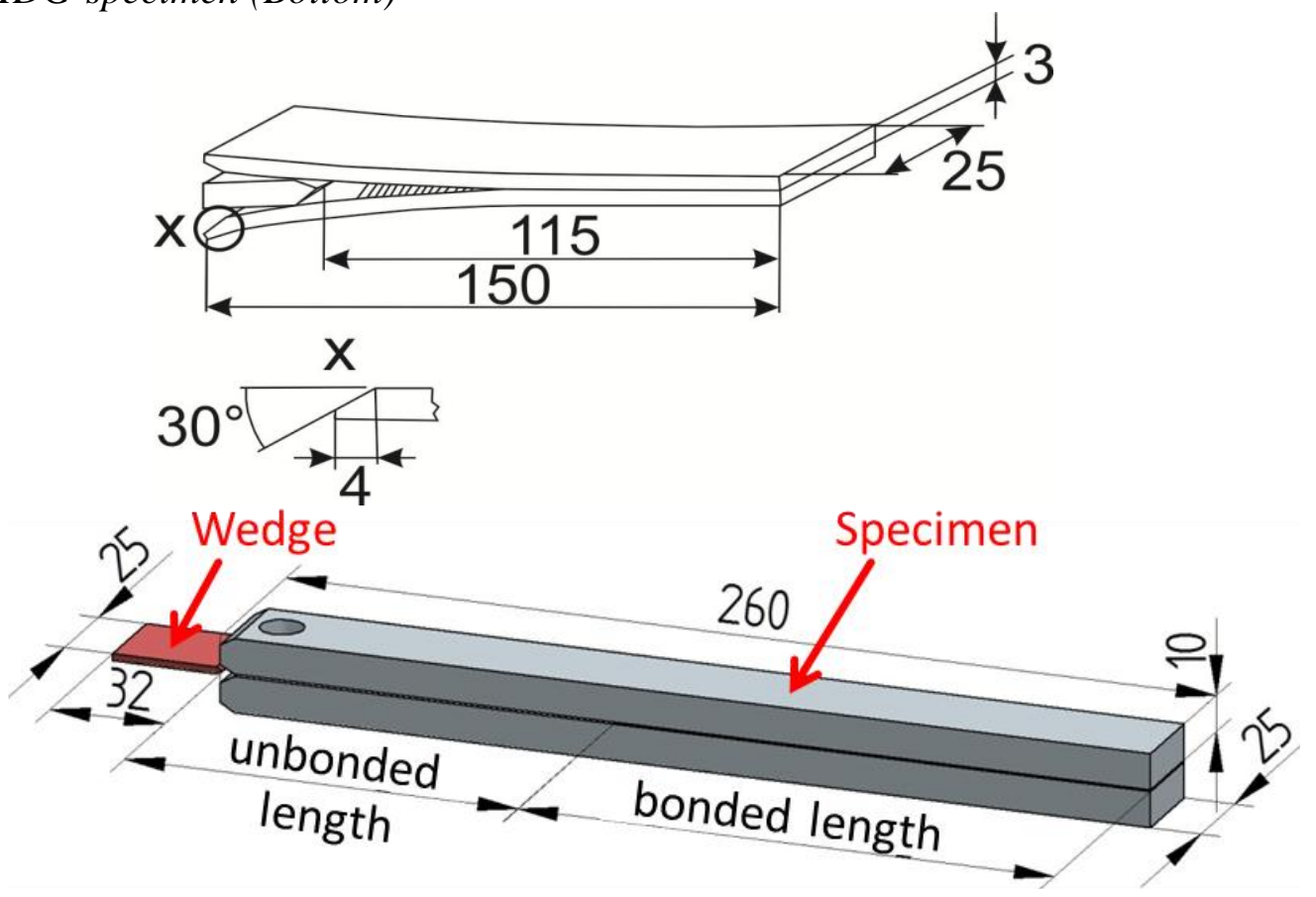

Crack progression was logged over time. The residual contact length after the time of exposure (t) allows a quantitative evaluation of the used adhesives in combination with the applied surface pre-treatments. The residual contact length $\left(\mathrm{L}_{\mathrm{R}}\right)$ is determined using the following context:

$\mathrm{L}_{\mathrm{R}}(\mathrm{t})[\%]=1-(\operatorname{crack}$ propagation $(\mathrm{t})[\mathrm{mm}] /$ bonded length $(\mathrm{t}=0)[\mathrm{mm}])$ 


\section{Results}

Ageing According to VDA 621-415

The results of five wedge test specimens per each selected adhesive and applied pre-treatment are shown in Figure 4. It contains the average value of the residual contact length of not completely detached specimens after 28 days of the climate corrosion test. The error bar indicates the standard deviation. Already, after 24 hours of the climate corrosion test, the initial part of notweathered and outdoor-weathered specimens is completely detached. After 28 days, just one specimen out of the two pre-treatments, shows a residual contact length. Sweep-blasted specimens show an average residual contact length in combination with SW 7260 and SP 477 of 40 to $50 \%$, however, 8 out of 15 specimens are already completely detached. Specimens pre-treated by SurTec ${ }^{\mathbb{R}}$ 479 and Bref Power ${ }^{\circledR}$ exhibit the biggest residual contact length after the climate corrosion test. Dependent on the used adhesives, a contact length of 60 up to $100 \%$ remains. Though that there is no significant difference between the test results of specimens pre-treated by SurTec ${ }^{\circledR} 479$ and Bref Power ${ }^{\circledR}$.

Figure 4. Residual Contact Length after 28 Days of Climate Corrosion Test

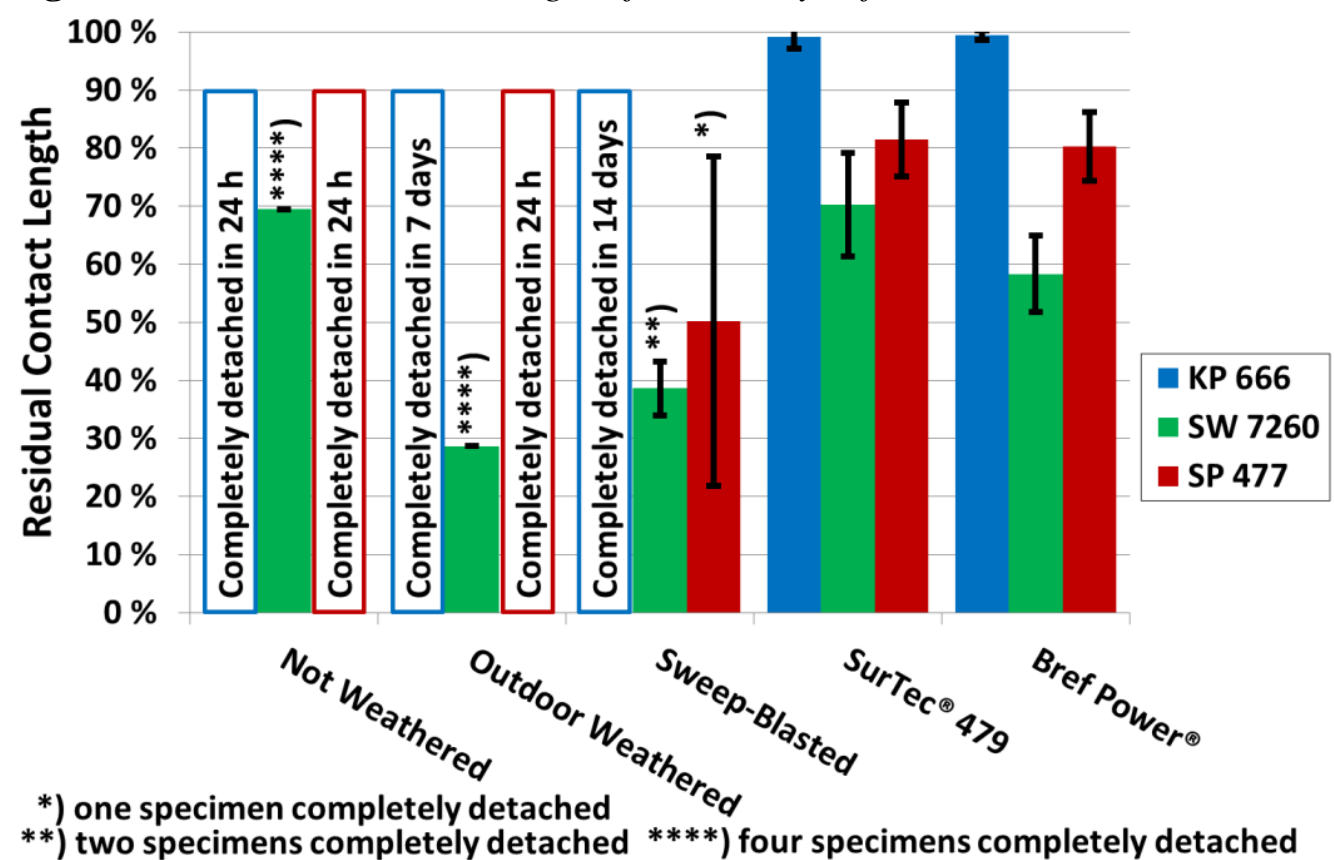

Ageing According to VW PV 1200

Figure 5 contains the residual contact length of the specimens after 28 days of alternating climate test. Within 48 hours, all not-weathered and outdoorweathered specimens were completely detached independent of the used adhesives. Sweep-blasted specimens bonded by KP 666 completely detached in $24 \mathrm{~h}$, bonded by the epoxy-based adhesives SW 7260 and SP 477 they detached within 18 days. 
Figure 5. Residual Contact Length after 28 Days of Alternating Climate Test

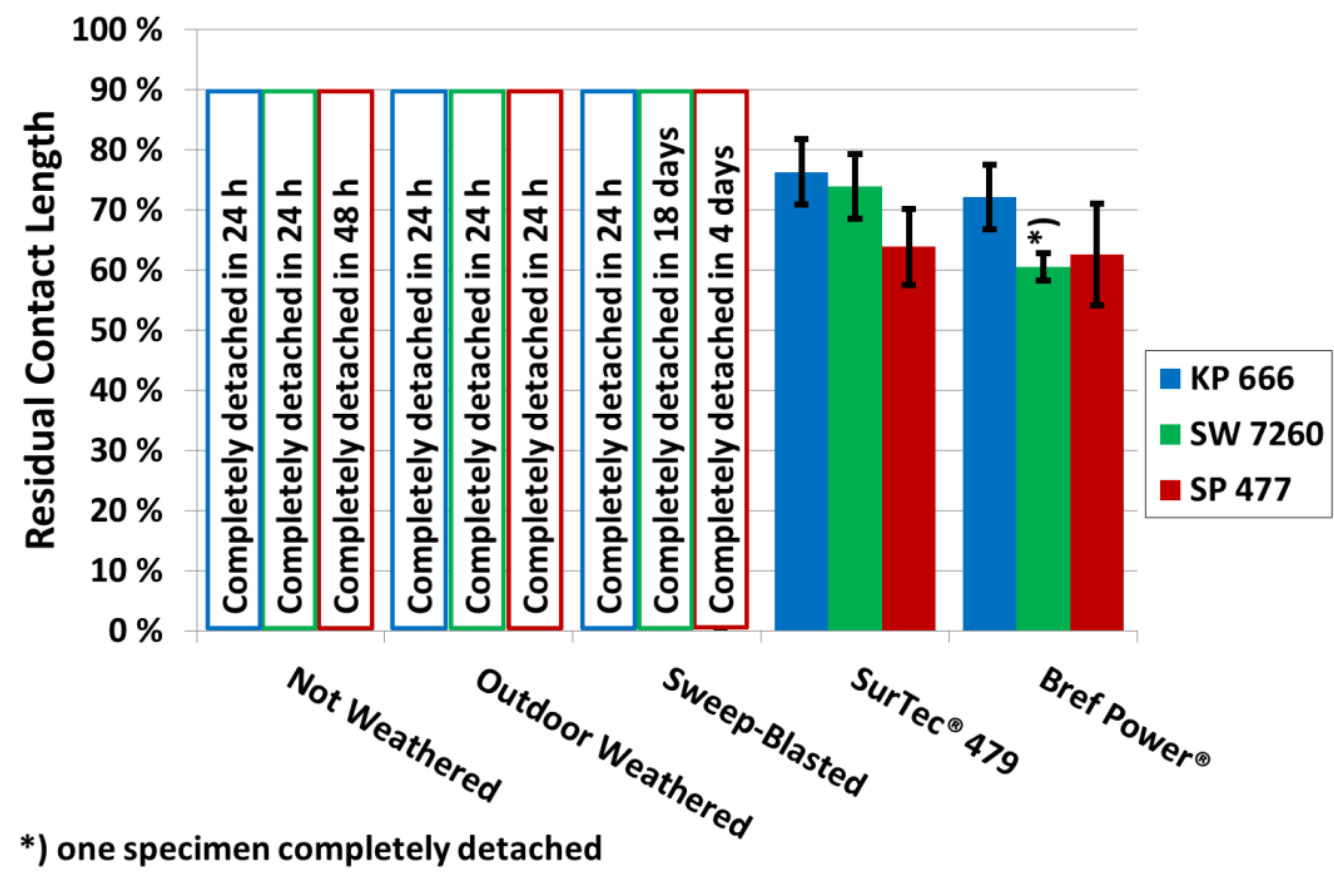

As well as in the climate corrosion test, after 28 days of alternating climate test specimens pre-treated by $\operatorname{SurTec}^{\circledR} 479$ and Bref Power ${ }^{\circledR}$ showed the biggest residual contact length. However, one specimen is completely detached. The residual contact length is between 60 and $80 \%$ for both applied pickling solutions. The average values are the same within the standard deviation for the three applied adhesives.

\section{Fracture Behavior of Wedge Test Specimens}

Usually, wedge test specimens show a more or less slow delamination failure between adhesive and adherent after initiation of the crack under certain climate conditions. Using sweep-blasted HDG-adherents in combination with SP 477 (lowest fracture elongation of the applied adhesives) sometimes an abrupt and complete delamination of specimens takes place. It happened while inserting the wedge, without any superposition of increased climate conditions. In these cases the zinc layer was removed from steel sheet surface occasionally by inserting the wedge. Figure 6 shows pictures of an abrupt completely detached specimen pre-treated by sweep-blasting and bonded by SP 477 . The micrograph demonstrates the two zinc layers still connected by the adhesive. 
Figure 6. Fracture between $\zeta$ - and $\delta_{1}$-phase of Zinc Layer

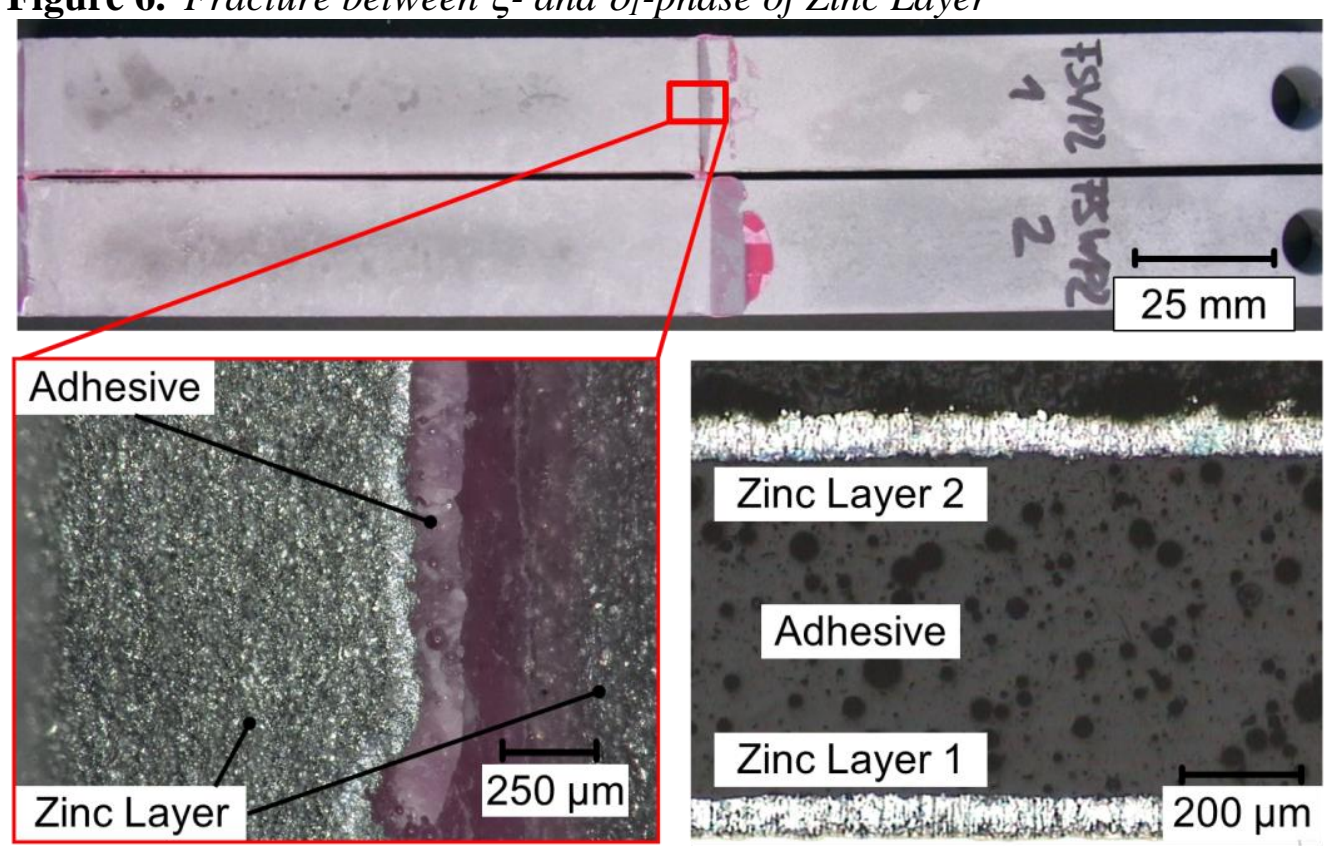

\section{Conclusions}

The wedge test as carried out in this experiment represents an economic test method with differentiable results regarding the durability of adhesively bonded joints within a few days. Applying climate corrosion and alternating climate tests, the wedge test shows on batch-galvanized steel sheets that the surface pre-treatments, which partially remove the zinc layer, can increase the durability of adhesively bonded joints significantly. Moreover the test shows no difference between the used ageing conditions on the adhesion of the batchgalvanized steel surfaces in combination with the applied adhesives. The impact of the grit during the sweep-blasting-process can create local defects in the zinc layer phases, so it will detach in combination with high-tensile and brittle adhesives applying a peel force. Biggest residual contact lengths after 28 days of accelerated ageing conditions remain while using the pre-treatments SurTec $^{\circledR} 479$ and Bref Power ${ }^{\circledR}$, independent of the applied adhesives.

\section{Acknowledgments}

The authors kindly acknowledge supporting by the Research Association for Steel Application (FOSTA), and funding by the German Federation of Industrial Research Associations (AiF) with grants from the Federal Ministry of Economic Affairs and Energy (BMWi). 


\section{References}

Che, C., Lu, J. And Kong, G. Interpretation on Sebisty effect of Hot-dip Galvanized Steels, Transactions of Nonferrous Metals Society of China, Vol. 15, No. 6, 2005, pp. 1275-1279.

de Lucas, C. G. Review of European Markets in 2009, Vienna (Austria): EGGA Assembly 2010, 2010.

Katzung, W. and Rittig, R. Zum Einfluss von Si und P auf das Verzinkungsverhalten von Baustählen [Influence of $\mathrm{Si}$ and $\mathrm{P}$ on the Galvanizing Behavior of Mild Steel], Materialwissenschaft und Werkstofftechnik, Vol. 28, Issue 12, 1997, pp. 575-587.

Maass, P. and Peissker, P. Handbook of Hot-dip Galvanization, Weinheim (Germany): Wiley-VCH Verlag, 2011.

Stahl, J. and Geiss, P. L. Kleben stückverzinkter Bauteile [Adhesive Bonding of Hotdipped Galvanized Steel], DVS-Report Volume 309 - PhD Seminar Adhesive Bonding, Düsseldorf (Germany): DVS Media GmbH, 2015, pp. 45-48.

Thiele, M., Schulz, W. D. and Schubert, P. Schichtbildung beim Feuerverzinken zwischen $435{ }^{\circ} \mathrm{C}$ und $620{ }^{\circ} \mathrm{C}$ in konventionellen Zink-Schmelzen - eine ganzheitliche Darstellung [Coating Formation during Hot-dip Galvanizing between $435{ }^{\circ} \mathrm{C}$ and $620{ }^{\circ} \mathrm{C}$ in Conventional Zinc Alloys - a Holistic Illustration], Materials and Corrosion, Vol. 57, Issue 11, 2006, pp. 852-867.

Ungermann, D., Oechsner, M., Friedrich, S., Rademacher, D., Landgrebe, R., Adelmann, J., Simonsen, F., Lebelt, P. Feuerverzinken im Stahl- und Verbundbrückenbau [Hot-Dip Galvanizing in Building and Construction of Steel- and Composite-Bridges]. Forschung für die Praxis (IGF-Nr. 351), Düsseldorf (Germany): Research Association for Steel Application (FOSTA), Report P 835, 2014.

Van Eijsenbergen, J. F. H. Duplex Systems: Hot-dip Glavanizing plus Painting, Amsterdam - London - New York - Tokyo: Elsevier, 1994, p. 61.

VDA 621-415. Testing of Corrosion Protection of Vehicle Paint by Alternating Cycles Test, Frankfurt (Germany): Verband der Automobilindustrie e.V., 1982.

VW PV 1200. Vehicle Parts - Testing of Resistance to Environmental Cycle Test (+80/-40) ${ }^{\circ} \mathrm{C}$, Wolfsburg (Germany): Volkswagen AG, 2004.

Wolczynski, W., Pogoda, Z., Garzel, G., Kucharska, B., Sypien, A., Okane, T. Part 1. Thermodynamic and Kinetic Aspects of the Hot dip ( $\mathrm{Zn})$ - Coating Formation. Metallurgy and Materials, Vol. 59, Issue 3, 2014, pp. 1223-1233. 
